\title{
Spray drying of the mixtures of mono-, di-, and oligosaccharides
}

\author{
Katarzyna Wrzosek, Juraj Moravčík, Monika Antošová, \\ Viera Illeová, Milan Polakovič \\ Department of Chemical and Biochemical Engineering, Institute of Chemical and Environmental Engineering, \\ Faculty of Chemical and Food Technology, Slovak University of Technology, \\ Radlinského 9, 81237 Bratislava, Slovakia \\ milan.polakovic@stuba.sk
}

\begin{abstract}
Optimal conditions of spray drying of a fructooligosaccharide-rich mixture prepared by enzymatic conversion of sucrose were investigated. It was found that efficient drying of the mixture containing about $40 \%$ of monosaccharides and sucrose required addition of a compound with a high glass transition temperature. The addition of maltodextrin helped to achieve satisfactory solids yield and moisture. Optimized process parameters were the feed flow rate and solids concentration, drying air flow rate and inlet temperature.
\end{abstract}

Keywords: spray drying, prebiotic oligosaccharides

\section{Introduction}

Prebiotic oligosaccharides are widely used in human diet due to their favorable effects on health. Prebiotic oligosaccharides are non-digestible and selectively promote growth of beneficial microflora of the intestine leading to various health benefits (Slavin, 2013). Galactooligosaccharides (GOS) and fructooligosaccharides (FOS) are the oligosaccharides most frequently used as active ingredients in functional foods. Both types of oligosaccharides occur naturally in some food, for example GOS are component of breast milk and FOS are present in some fruits and vegetables. In the last decades, a high demand for prebiotic oligosaccharides promoted the growth of their industrial production. Both GOS and FOS are usually produced by enzyme synthesis from appropriate disaccharides (lactose or sucrose) when monosaccharides, mainly glucose, are formed as by-products. A product of this biosynthesis is either sold as syrup or it is finalized by spray drying to get a powder form. GOS are mostly used in infant diet such as infant formula milk powders and yoghurts whereas FOS are used as ingredients into sweet bakery products, beverages, or yoghurts.

Spray drying is a method of obtaining a dry powder often used in the production of foods and pharmaceuticals. In this process, a solution containing compounds of interest is first sprayed into droplets sized in the range from 10 to $500 \mu \mathrm{m}$. The droplets are rapidly dried by hot air. Since the spray drying can be performed fast and at temperatures below water boiling point, this technique is feasible for drying of thermally sensitive materials. The obtained powder is convenient for transport and storage due to weight and volume reduction and better preservation of dried components.
Spray drying of sugar-rich mixtures is however a challenging task. The process often suffers from a low recovery due to high deposition of sugars on the spray dryer walls. The solutes remaining on the drying chamber walls are overheated due to a long exposition to high temperatures and do not meet high quality requirements of the final product (Wang and Langrish 2009). Another issue is a co-adhesion of dried particles. The resulting clusters are heavy and are not properly transported to a cyclone. Both phenomena are a consequence of high stickiness of the mixtures with a high concentration of low-molecular weight sugars (Adhikari et al. 2003).

The stickiness of sugars such as fructose, glucose, and sucrose is due to their thermoplastic behavior (Truong et al. 2005, Wang and Langrish 2009). These materials become sticky when they are heated to a temperature equal or higher than their stickypoint and change from a glassy to a liquid-like rubbery state. The temperature of the sticky-point is about $10-20{ }^{\circ} \mathrm{C}$ higher than the glass transition temperature $\left(T_{g}\right)$ (Roos and Karel 1991; Bhandari et al. 1997a; Bhandari and Howes 1999). The glass transition temperature of low molecular weight sugars is low and their high content in a material reduces its $T_{g}$ below the temperature at the dryer outlet leading to a sticky product. The higher is the difference between the outlet (final product) temperature and $T_{g}$, the higher is the degree of stickiness and the higher are the losses due to the formation of wall deposits.

The yield of spray drying of sugar-rich materials can be increased by addition of proper drying additives. The most frequently used method involves a use of aids with high $T_{g}$ such as maltodextrin (Bhandari et al. 1997b; Adhikari 2004; Truong et al. 2005). 
For a multi-component mixture, $T_{g}$ is a function of the mass fractions of all components and their $T_{g}$-values. Therefore, the addition of maltodextrin, with the $T_{g}$-value as high as $205^{\circ} \mathrm{C}$ for a maltodextrin with the dextrose equivalent of 6 , increases the overall $T_{g}$ of the newly-formed mixture and makes spray drying easier. Maltodextrin is a popular food additive also due to its relative low sweetness and easy digestion. In the case of products with very high content of di- and especially monosaccharides, the amount of maltodextrin required to successfully facilitate spray drying can even exceed $50 \%$ of solute mass (Wang and Langrish 2009). Such high concentration of maltodextrin is often undesirable. It increases the production costs and leads to alteration of final product flavor and texture. For these reasons, it is advantageous to optimize spray drying conditions in a way that would allow efficient drying with a minimal use of maltodextrin.

In this paper, we present the results of optimization of spray drying of a FOS-containing mixture. This topic has not been reported in literature before. The FOS-rich mixture used in this study was a product of sucrose conversion using fructosyltransferase (FTase) that is why it contained considerable amounts of sucrose and glucose. The low-molecular weight sugars significantly affected thermoplastic behavior of the mixture making the drying of the material more difficult. Various spray drying conditions were tested to find an optimal spray drying regime. The influence of inlet temperature, feed rate and maltodextrin content were studied.

\section{Materials and methods}

\section{Materials}

A fructosyltransferase extract was obtained as described previously (Vandáková et al. 2004). Dowex Marathon MSA is a product of Dow Chemical (Midland, USA), maltodextrin Glucidex 19 is a product of Roquette (Lestrem, France) and sucrose, citric acid and sodium phosphate were of analytical grade and obtained from readily available sources.

\section{Enzyme immobilization}

Fructosyltransferase was immobilized on an anion exchanger Dowex Marathon MSA using a method developed by Platková et al. (2006). The adsorbent was washed and equilibrated with a $20 \mathrm{mM}$ citratephosphate buffer with the $\mathrm{pH} 5.5$. The initial fructosyltransferase preparation in the same buffer with the enzymatic activity of $48000 \mathrm{U} / 1$ was added to Dowex Marathon MSA particles in 3:1 volume ratio and mixed for two hours. The suspension was then left for 12 hours at $4{ }^{\circ} \mathrm{C}$. After immobilization, the unbound protein was washed with the citrate- phosphate buffer. The immobilization efficiency was $52 \%$ and particles with the specific activity of $85000 \mathrm{U} / 1$ were obtained.

\section{FTase activity assay}

$300 \mu \mathrm{l}$ of enzyme solution or $0.7 \mathrm{~g}$ of immobilized enzyme was added into $5 \mathrm{ml}$ of $700 \mathrm{~g} / 1$ sucrose solution prepared in a $20 \mathrm{mM}$ phosphate-citrate buffer with $\mathrm{pH} 5.5$. The reaction was carried out at $55^{\circ} \mathrm{C}$ and stopped by exposing the sample to $100^{\circ} \mathrm{C}$ for 2-3 $\mathrm{min}$. The amount of glucose produced in the reaction was determined using a glucose assay with the Bio-La-Test Glucose GOD (Pliva-Lachema Diagnostika, Brno, Czech Republic). One unit of transfructosylation activity was defined as the amount of enzyme producing $1 \mu \mathrm{mol}$ of glucose during $1 \mathrm{~min}$.

\section{FOS production}

A Pharmacia XK 26 column $(800 \times 26$ mm I.D., GE Healthcare, Little Chalfont, UK) was packed with $330 \mathrm{ml}$ of the immobilized FTase. $700 \mathrm{~g} / 1$ sucrose solution was continuously fed to the packed-bed reactor for 1 week at the flow rate of $2 \mathrm{ml} / \mathrm{min}$, which corresponded to the residence time of about $90 \mathrm{~min}$. The reaction was carried out at $47.5^{\circ} \mathrm{C}$. The composition of the reactor outlet stream was monitored continually. The mean sucrose conversion during the one-week operation reached $89.5 \%$. 1-kestose and nystose were the main FOS components forming about $70 \%$ of all fructooligosaccharides (Onderková 2010). Besides FOS and un-reacted sucrose, the final product contained also glucose which was formed as a by-product of transfructosylation reaction (Antošová et al. 2008). Table 1 shows the composition of the final FOS-rich mixture.

Tab. 1. Composition of FOS-rich mixture.

\begin{tabular}{ccc}
\hline Component & $\begin{array}{c}\text { Concentration } \\
{[\mathbf{g} / \mathbf{l}]}\end{array}$ & $\begin{array}{c}\boldsymbol{T}_{\boldsymbol{g}}\left[{ }^{\circ} \mathbf{C}\right] \\
\text { (Blanch et al 2012) }\end{array}$ \\
\hline Fructose & 11.3 & 12.6 \\
Glucose & 208.0 & 35.5 \\
Sucrose & 73.2 & 68.3 \\
Total FOS* & 407.5 & 91.2 (1-kestose), \\
& & 102.2 (nystose) \\
\hline
\end{tabular}

${ }^{*}$ Due to incomplete separation of individual FOS only the total concentration could be determined.

\section{HPLC analysis}

HPLC analysis of saccharides was performed using Agilent HPLC 1200 equipped with an RI detector (Agilent Technologies, Santa Clara, USA). The composition of the FOS-rich mixture produced in the packed-bed reactor was determined using 


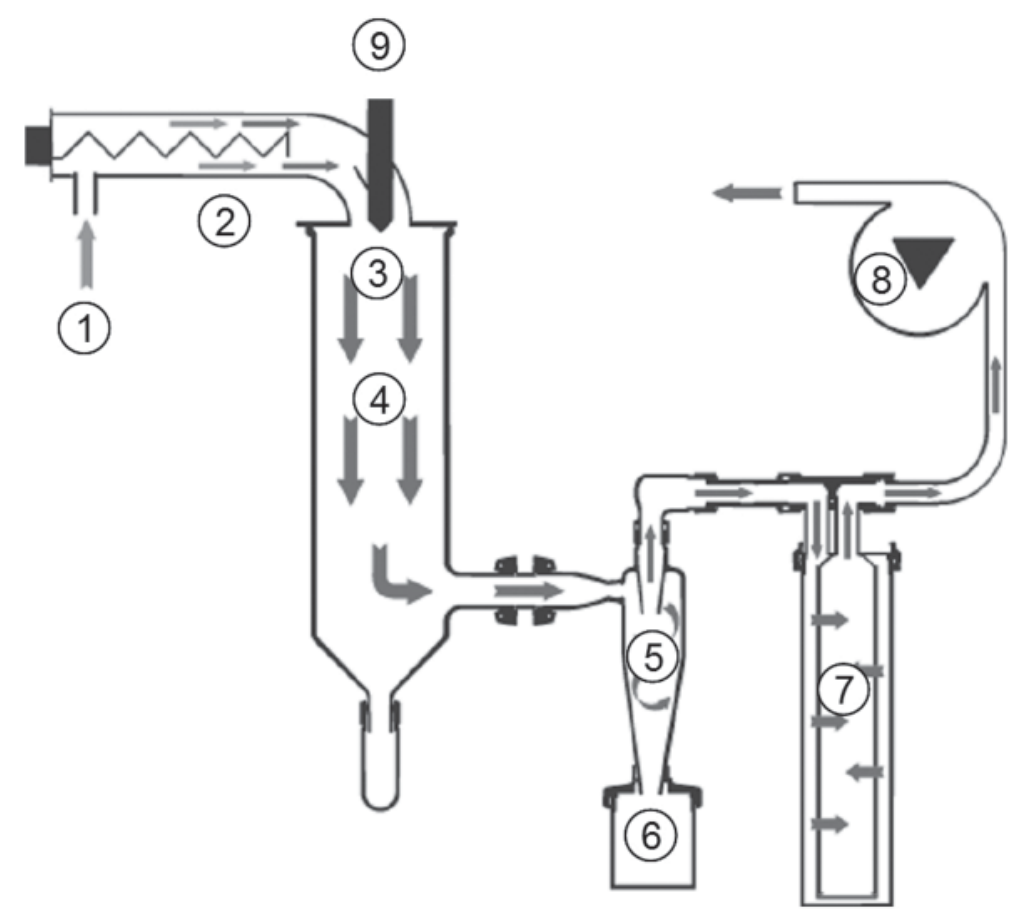

1 Gas inlet, 2 Electric heater, 3 Two fluid nozzle, 4 Spray cylinder, 5 Cyclone, 6 Product collection vessel, 7 Outlet filter, 8 Aspirator, 9 Feed

Fig. 1. Flow diagram of Büchi's Mini Spray Dryer B290 with co-current flow of liquid and gaseous streams (reproduced with permission).

the column Eurokat Na $(250 \times 20 \mathrm{~mm}$ I.D., Merck $\mathrm{KGaA}$, Darmstadt, Germany) at $60^{\circ} \mathrm{C}$ with water as a mobile phase at the flow rate of $1.5 \mathrm{ml} / \mathrm{min}$. The composition of maltodextrin-containing mixtures before and after spray drying was determined using Eurokat $\mathrm{Pb}$ column $(300 \times 8 \mathrm{~mm}$ I.D, Merck KGaA, Darmstadt, Germany) at the temperature of $80{ }^{\circ} \mathrm{C}$ with water as mobile phase at the flow rate of $0.6 \mathrm{ml} / \mathrm{min}$. Maltodextrin was eluted as a single uniform peak with the lowest retention time.

\section{Spray drying}

$60 \mathrm{ml}$ samples of FOS-rich and FOS/maltodextrin mixtures were spray-dried with air as a drying gas using the equipment Mini Spray Dryer B-290 (Büchi Labortechnik, Flawil, Switzerland). The process is illustrated in Fig. 1. The total sugar concentration of the FOS-rich mixture was between 280 and $700 \mathrm{~g} / 1$. The inlet temperature varied between $110-130{ }^{\circ} \mathrm{C}$, the spray gas flow rate was set to $400-1000 \mathrm{l} / \mathrm{h}$, the feed flow rate was in a range $1.4-10 \mathrm{ml} / \mathrm{min}$ and the aspirator rate was kept at $100 \%$. The FOS/maltodextrin solutions contained $300 \mathrm{~g} / 1$ or $450 \mathrm{~g} / 1$ of the FOS-rich mixture and $300 \mathrm{~g} / 1$ or $150 \mathrm{~g} / 1$ of maltodextrin. $T_{i n}$, the inlet air temperature of $90-120^{\circ} \mathrm{C}$ was used, the feed flow rate was set between 1.4 and $6.2 \mathrm{ml} / \mathrm{min}$ and the aspirator rate was kept at $100 \%$. It was found the content of individual saccharides was not changed by spray drying.

\section{Results and discussion}

The first step of this investigation was the spray drying of FOS-rich solutions. The total sugar concentration was adjusted by dilution of the product obtained from the packed-bed reactor. The concentrations between 280 and $700 \mathrm{~g} / \mathrm{l}$ were tested. Other drying parameters such as the inlet air temperature, the feed and gas flow rates were also varied as described in the previous section. In most cases, the dried material was highly sticky. Due to exorbitant depositing in the drying chamber, almost no dry product was collected. Only at the lowest feed flow rate, the amount of dried product was sufficient for quantification. The highest yield of $16 \%$ was obtained at $T_{\text {in }}$ of $120{ }^{\circ} \mathrm{C}$ and the total sugar concentration of $280 \mathrm{~g} / 1$.

The highest spray gas flow rate of $1000 \mathrm{l} / \mathrm{h}$ was the most effective and was used in all subsequent experiments. Low to moderate values of the feed concentration combined with a low feed rate decreased the wall deposits to some extent. Nevertheless, the stickiness problem remained and obtained yields were very low. The obtained outlet air temperature values $T_{\text {out }}$ (corresponding to the maximum temperature of dried solids) were between 75 and $87^{\circ} \mathrm{C}$. Although these values are in a range of typical $T_{\text {out }}$ used for sticky materials (Adhikari et al. 2005), the drying was unsuccessful due to the high amount of 
mono- and disaccharides in the FOS-rich mixture (Table 1). The presence of $42 \%$ of glucose, fructose and sucrose with the $T_{g}$-values below the obtained $T_{\text {out }}$-values significantly decreased the overall value of $T_{g}$ of the FOS-rich mixture. Since the glass transition temperature of a mixture is a function of $T_{g}$ values and mass fractions of all components, the low overall $T_{g}$ of the FOS-rich mixture led to the existence of a liquid-like state of the dried material and to a high degree of particle cohesion and adhesion on the dryer surface.

To overcome the problem of stickiness, the FOS-rich mixture was mixed with maltodextrin for further spray drying experiments. A single total dry-mass concentration of $600 \mathrm{~g} / 1$ was used when the maltodextrin concentration was either 150 or $300 \mathrm{~g} / \mathrm{l}$. In both cases, $T_{\text {in }}$ of 90,110 and $120^{\circ} \mathrm{C}$ and feed flow rates of 1.4 and $6.2 \mathrm{ml} / \mathrm{min}$ were used. The solids moisture and yield values obtained are presented in Table 2 . These results clearly demonstrated a benefit of the use of a lower flow rate. The solids yield values were much higher at the flow rate of $1.4 \mathrm{~mL} / \mathrm{min}$. At these conditions, a lower solvent evaporation was needed. On the other hand, the higher feed flow rate of $6.2 \mathrm{~mL} / \mathrm{min}$ caused the decrease of $T_{\text {out }}$-values and increase of solids moisture. Since the glass transition temperature decreases with water content (Hatekeyama et al. 1989), the lower solids yields at the higher feed flow rate can be attributed to adhesion phenomena in the drying chamber.

Table 2 further shows that the feed composition had a strong impact on the process yield. As could be expected, the higher concentration of maltodextrin ensured more effective spray drying. The solids yield exceeded the values of $50 \%$ in most cases. It was smaller only at the higher feed flow rate combined with a lower $T_{i n}$. The best performance of the drying process was observed at the lower feed flow rate and 1:1 maltodextrin to the FOS-rich mixture ratio. The yields of about $60 \%$ were achieved independent of $T_{\text {out }}$ and $T_{i n}$. The solids with a lower content of maltodextrin, 1:3 in this case, would be of course more attractive for further applications. Interesting solids yield values close to $50 \%$ were obtained at the feed flow rate of $1.4 \mathrm{ml} / \mathrm{min}$ and $T_{\text {in }}$ of 110 and $90{ }^{\circ} \mathrm{C}$, respectively. A somewhat lower value of $T_{\text {out }}$ was thus favorable for drying of sticky materials if the content of maltodextrin was reduced (Adhikari et al. 2004). Solids moisture below $2 \%$ was obtained in all cases but two where the maltodextrin content was higher and $T_{\text {in }}$ was $90^{\circ} \mathrm{C}$. This slower evaporation rate can be attributed to higher viscosity and lower diffusivity at these conditions.

\section{Acknowledgement}

This work was supported by the Agency of the Ministry of Education, Science, Research and Sport of the Slovak Republic for the Structural Funds of EU under the grant number ITMS 26240220057.

\section{References}

Adhikari B, Howes T, Bhandari BR, Troung V (2004) Journal of Food Engineering 62: 53-68.

Adhikari B, Howes T, Lecomte D, Bhandari BR (2005) Powder Technology 149: 168-179.

Adhikari B, Howes T, Troung V (2003) Drying Technology 21: 839-873.

Antošová M, Illeová V, Vandáková M, Družkovská M, Polakovič M (2008) Journal of Biotechnology 135: $58-63$.

Bhandari BR, Datta N, Crooks R, Howes T, Rigby S (1997a) Drying Technology 15: 2509-2525.

Tab. 2. Results of spray drying of FOS/maltodextrin mixtures.

\begin{tabular}{|c|c|c|c|c|c|}
\hline Feed type ${ }^{*}$ & $\begin{array}{c}T_{\text {in }} \\
{\left[{ }^{\circ} \mathrm{C}\right]}\end{array}$ & $\begin{array}{c}T_{\text {out }} \\
{\left[{ }^{\circ} \mathrm{C}\right]} \\
\end{array}$ & $\begin{array}{c}\text { Feed flow rate } \\
{[\mathrm{ml} / \mathrm{min}]}\end{array}$ & $\begin{array}{c}\text { Solids yield } \\
{[\%]} \\
\end{array}$ & $\begin{array}{c}\text { Solids moisture } \\
{[\%]}\end{array}$ \\
\hline \multirow{6}{*}{$1: 1$} & 120 & 84 & \multirow{3}{*}{1.4} & 57.3 & 0.3 \\
\hline & 110 & 78 & & 61.6 & 0.3 \\
\hline & 90 & 65 & & 57.7 & 2.4 \\
\hline & 120 & 77 & \multirow{3}{*}{6.2} & 53.8 & 1.0 \\
\hline & 110 & 70 & & 37.6 & 1.2 \\
\hline & 90 & 57 & & 29 & 2.1 \\
\hline \multirow{6}{*}{$3: 1$} & 120 & 86 & \multirow{3}{*}{1.4} & 39.7 & 0.6 \\
\hline & 110 & 78 & & 46.9 & 0.8 \\
\hline & 90 & 65 & & 47.3 & 1.0 \\
\hline & 120 & 77 & \multirow{3}{*}{6.2} & 18.4 & 0.5 \\
\hline & 110 & 69 & & 19.9 & 0.6 \\
\hline & 90 & 55 & & 17.1 & 1.6 \\
\hline
\end{tabular}

*It expresses the mass ratio of FOS-rich mixture saccharides and maltodextrin in the feed. 
Bhandari BR, Datta N, Howes T (1997b) Drying Technology 15: 671-684.

Bhandari BR, Howes T (1999) Journal of Food Engineering 40: 71-79.

Blanch M, Goñi O, Sanchez-Ballesta MT, Escribano MI, Merodio C (2012) Food Chemistry 135: 912-919.

Hatakeyama T, Nakamura K, Yoshida H, Hatakeyama, H (1989) Food Hydrocolloids 3: 301-311.

Onderková Z (2010) PhD Thesis, Slovak University of Technology, Bratislava.

Platková Z, Polakovič M, Štefuca V, Vandáková M, Antošová M (2006) Chemical Papers 60: 469-472.
Roos YH, Karel M (1991) Journal of Food Science 56: $38-43$.

Slavin J (2013) Nutrients 5: 1417-1435.

Truong V, Bhandari BR, Howes T (2005) Journal of Food Engineering 71: 55-65.

Vandáková M, Platková Z, Antošová M, Báleš V, Polakovič M (2004) Chemical Papers 58: 15-22.

Wang S, Langrish T (2009) Food Research International 42: 13-25. 